\title{
Image composition influences on the mood board visual reading process through eye-tracking
}

\author{
Marcos Roberto dos Reis ${ }^{\mathrm{a} *}$ (D), Eugenio Andrés Díaz Merino ${ }^{\mathrm{a} *}$ (D) \\ aPrograma de Pós-graduação da Engenharia de Produção - PPGEP, Universidade Federal de Santa Catarina - UFSC, Florianópolis, SC, Brasil
}

\begin{abstract}
Mood boards (MB) are a visual tool used to provide references for inspiration and decision-making in the design development process. However, it isn't easy to obtain objective and precise measures about the MB organization if exclusively qualitative approaches identify how the image composition can affect the visual reading process. In this sense, this study aimed to evaluate how the position and physical image aspects influence an attentive MB visual reading. The results presented that variations in image contrast and positioning influence the observer's visual reading. Besides, the observers' identified tendencies were to concentrate the visualisations in the boards' central, lower and left areas, indicating the importance of this region's MB construction. Moreover, the results evidence that the visual reading of an MB presents a different pattern from those reported by studies directed to analysing the visual reading of websites. Thus, changes in image positioning influenced the viewer's perception, being a relevant point to be considered when assembling the MB's image composition. The results of this study contribute to creating criteria for the construction of MB.
\end{abstract}

Keywords: mood boards, design tools, boards composition, perception.

\section{Introduction}

Mood boards (MB) are visual tools used in various parts of the design development process to convey an orientation, vision, or idea to different stakeholders (Chang et al., 2014; Lucero, 2012; McDonagh \& Denton, 2005). These boards help to serve as a tangible object, a visual reminder to inspire solution principles (Martin \& Hanington, 2012). Made up predominantly of images, MB are considered an easy, quick, and organised way of visually referring to a specific technical design, concepts alignments or aesthetic attributes. In this context, the MB presents itself as an important resource for developing a product, making visually technical, aesthetic, and symbolic elements available to subsidise design decisions (Löbach, 2001).

The MB construction process involves selecting and composing images, colours, lines, textures, words and objects in a defined space (Cassidy, 2011; Edwards et al., 2009; Lucero, 2015). For its semantic characteristic, images are an appropriate resource to convey meanings, particularly values and emotional experiences (Bruseberg et al., 2003). The evaluation of an MB, regarding its content, context and visual appearance, should be considered an inherent part of the creation process, the decisions made, the reasons for those decisions, and the reflections undertaken (Cassidy, 2011). Product designers use them to explicitly represent spaces, movements, surfaces, and materials (Lucero, 2012). In contrast, graphic designers choose images for visual qualities, such as colours, font characteristics, and textures, to stimulate design associations (Lucero, 2012).

It has already been evidenced that each MB is constituted according to the context needs, with visual elements positioned and directed to meet different project demands (Baxter, 2011; Gade, 2016). Due to the imagery resources being increasingly used in different product development stages and the scientific community to disseminate the results obtained, developing MB guidelines can turn more efficient in transmitting helpful information for decision-making.

The MB composing activity is associated with the image elements' subjective choices, associating creativity, personal experiences, and cultural context to the board (Gonçalves et al., 2014; McDonagh \& Denton, 2005). For Edwards et al. (2009), there is no existing methodology for MB composition, being creativity and imagination the primary resources used in this activity. The MB composition activity starts from personal or group image choices, using creativity, individual preferences, and cultural context (McDonagh \& Denton, 2005), resulting in unique compositions, visual elements, and the way they are fixed and presented. When composing an MB, several relevant factors must be taken into consideration, including not only the positions of visual elements within the board, oriented to aesthetically balanced composition (Arnheim, 2004), but also: their colours (P. Locher et al.,

Received: September 3, 2021. Accepted: October 6, 2021.

*Corresponding author: Marcos Roberto dos Reis. E-mail: mreis@uffs.edu.br; Eugenio Andrés Díaz Merino. E-mail: eugenio.merino@ufsc. 
2005); orientations (Locher \& Stappers, 2002); sizes, and shapes (Hübner \& Thömmes, 2019; Wilson \& Chatterjee, 2005). A balanced composition points to a tendency to distribute visual elements throughout the physical space of the board (Leyssen et al., 2012).

$\mathrm{MB}$ are commonly observed in effective attention conditions, where there is a selective search for visual elements, symbols, shapes and colours in the set and details of images. Visual reading sequence, carried out systematically, plays a central role in how information is perceived and absorbed. Previous studies assessing user reactions to a range of websites have shown that the location of an element is a critical factor in determining its place in the viewing order (Djamasbi et al., 2011). Hence, understanding how different observers view an MB favours better control over its composition, benefiting communication and the reading experience. This visualisation can be achieved through a targeted selection of elements and attributes, such as size and position (Faraday, 2000). Thus, the images position or other visual elements can affect the reading process by including prominent features that attract attention to a particular point of the board.

Developing a study on proper positioning and selecting images for an MB is one of the gaps to be filled by design professionals (Koch et al., 2020). Moreover, the step-by-step process of building an MB is a process evidenced by many works (Cassidy, 2011; Lucero, 2015; Rieuf, 2013). However, within the different stages of building an $\mathrm{MB}$, there are processes, such as positioning and the choice of image, which require more evidence (Koch et al., 2020).

In this sense, organising an MB should cover aesthetic concerns and technical aspects favouring visual reading control, making the message more evident and efficient. Baxter (2011) showed that an MB could trigger different feelings in the users. Therefore, the dynamics of using an image (positioning, framing, dimensions, details) are substantial factors for the development of an $\mathrm{MB}$, as it is a relevant tool for users to express their emotions, expectations and views (McDonagh et al., 2002).

Given this, highlighting the influence of positioning, dimensions, format and details of images in MB can allow a better domain over this construction process, making it more controlled and efficient. In this sense, the aims of this study evaluated, through an objective approach, how the position and physical image characteristics influence an attentive MB visual reading. Thus, this study shows a closer understanding of the visual reading process of an MB composition.

In order to elucidate the above questions, this research was conducted based on separate stages linked to the selection of observers, the visualisation of different MB with the use of eye-tracking glasses and, finally, the analysis of the collected data. Thus, the influence that images exert on the visual reading of distinct MB formats were identified.

\section{Mood boards}

Godlewsky (2008, p. 266) defines MB as "[...] a collage implemented to introduce a certain mood, theme, or consumer world". The collage of previously selected images intent to hold significant details about different qualities of the desired product. It can also help the team assimilating the mood of a form of creation's values. MB have two essential elements, a board and a message (Cassidy, 2011). The board can be made of any flat and unmarked material, which serves as a centralising and aggregating area for a message. The board is a critical part of the tool and requires a good perception of those who build them to guide the design team correctly. The MB message is characterised by a set of visual elements previously selected and randomly arranged on the flat board (McDonagh \& Denton, 2005). A poorly constructed MB can drive messages not in tune with the aesthetical specifications (Garner \& McDonagh-Philp, 2001). Pazmino (2015, p. 105) suggests that the board would be "[...] assembled with images, however, one should consider that a text gives greater emphasis to the characteristics of the image, not least because the image alone can be misinterpreted". In this sense, the use of a wide range of visual elements for the composition of the board is highly encouraged, as long as they are aligned with the context, such as landscape photographs, small objects, words, artistic drawings (own or others), sketches of stylistic details, geometric shapes, random lines, scents, textures. Anything that can generate a composition of elements capable of transmitting a strong message about meaning is appropriate and harmonised on the board.

As for the MB visual organisation, they can be assembled in different configurations (Figure 1): (1) as a collection of images in which each one represents something (Yamani et al., 2010); (2) as a collection of images that look like or are related to something (Cassidy, 2008); or (3) as a collection of images, having a central one and flanked by others that support it, related to something (McDonagh \& Denton, 2005). Pereira (2010, p. 39) comments that "while some professionals choose to separate the board references in aspects to be planned (colour palette, accessories, environments, for example) and others seek to approximate them to facilitate the expression of an idea, some designers work with a logic of construction undefined". 


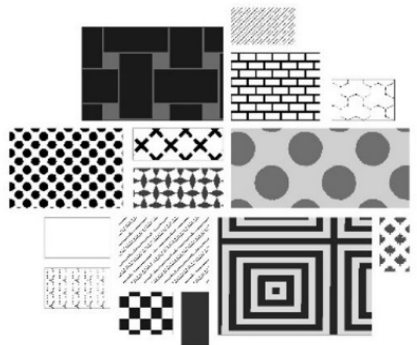

(1)

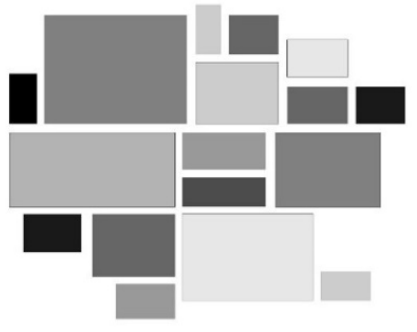

(2)

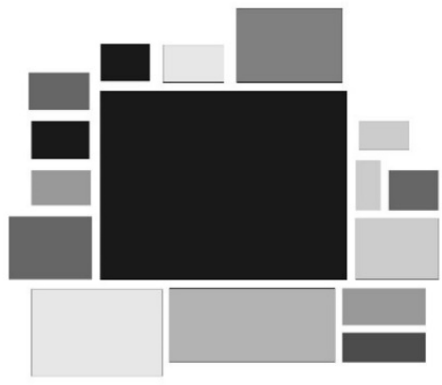

(3)

Figure 1. Different configurations of MB visual organisation.

\subsection{Visual reading}

Visual reading, exploring a specific item or object in a scene, is a ubiquitous part of human visual behaviour (Findlay \& Gilchrist, 2003). It involves more than the contemplative observation that occurs when one unassumingly observes some landscape. When proceeding with visual reading, an object is analysed and visualised with attention to perceive all the form nuances and details, its surroundings and the context in which it is located, seeking to understand the messages and meanings of this set (Collewijn, 1998). This analysis identifies and evaluates the elements that make up an object under study, including finish, technical information, structural details, and other specifications.

The scanning process for visual information begins in the centre, but the paths of the reading sequence may vary. Hooge \& Erkelens (1998) used circular displays in an experiment and reported that subjects tended to scan clockwise or counterclockwise around the display. Zelinsky et al. (1997) observed another pattern in an experiment with a small number of items on a table, that subjects made several saccades to locate the target. Fixation positions analysis of the saccades during the scanning path showed that they were initially directed toward the centre of the item groups and progressively focused on smaller details.

Looking is not something passive and, according to Pylyshyn (2003, p. 160), “[...] we affect what we see when we choose where to look. Indeed, changing our direction of gaze by moving our eyes is one of the main ways in which we selectively adjust the visual world." However, there are some common characteristics regarding the way this occurs. The selective search for elements of interest usually has, as a matter of naturalness, its beginning in the centre of an image or object (Arnheim, 1982, p. 4). It is the first contact with the visual element, recognising that there is something to be explored in that place. Next, the eye is attracted to some point of interest and makes a whole object visual reading. Internet sites, for example, tend to have the upper left corner as its most valued part, for being the first to receive effective attention from the reader (Damasceno \& Gruszynski, 2014; Faraday, 2000). It keeps some relation with reading texts in occidental culture, which has the same place as the initial point of attention.

According to Sternberg (2010, p. 107), “[...] attention is how a limited amount of information is actively processed from the enormous amount of information available through the senses, stored memory, and other cognitive processes". Attentively observing an object requires a person to focus on a small part of it to absorb the available information and process it properly. Attention, in turn, allows one to select some of the available visual information for longer or more detailed analysis (Findlay \& Gilchrist, 2003, p. 3).

Attentive visual reading applies to any object. Searching comprises actively and skillfully seeking a target (Pashler, 1999). When a person reads an MB image, it works with attention, essentially in the search function, looking for semantic elements matching a personal reference (Sternberg, 2010). The purpose is to select these elements as a visual reference, team alignment, or stimulus to create concepts and comparisons.

When it comes to design tools, such as $\mathrm{MB}$, attention plays a relevant role for the designer when analysing details of the images and capturing helpful information for application in the project. By studying the visual reading procedure, one seeks to increase the efficiency of the tool's application and, consequently, the results provided to the project.

\section{Methodological procedure}

In order to evaluate the image dynamics in different types of $\mathrm{MB}$, an individual eye-tracking reading capture was conducted for data collection. This methodology was employed to identify whether the positioning of different images and the image style can affect the visualisation of an MB. Subsequently, the data were analysed with a statistical basis and thus presented.

Eye-tracking allowed examining the user's reaction to viewing the MB in real-time. Eye-tracking makes it possible to record the movement the eyes make when scrolling through an image. It examines the user's reaction to viewing the boards 
in real-time, while traditional methods (interviews, focus groups, questionnaires) are flawed because they depend on the willingness and competence of the participants to describe how they feel when they are exposed to some stimulus

For data collection, participants' choice used, as inclusion criteria, design undergraduate course students at Federal University of Santa Catarina (southern Brazil), enrolled in Project VI subject, and MB familiarised. Twelve participants were selected, read and accepted the Informed Consent Form (ICF) terms. According to Pernice \& Nielsen (2009), in a qualitative eye-tracking study, six users are considered enough to assess the main usability issues accurately. After putting on the eye-tracking goggles, adjustments and calibration of the equipment, the participants were instructed to observe three different MB for a total time of 120 seconds $(3 \times 40 \mathrm{~s})$. The application of the procedure had an average duration of 8 minutes per participant.

The experiment to capture the visual reading through the eye-tracking equipment included preparing two MB sequences to stimulate and capture the observation profile in each one of them. The difference between the two sequences is in the MB used, with similar composition and identical images, but with changes in their positioning. In this sense, five boards were prepared, divided into three types: A, B, and C. Thus, 6 people observed the MB sequence 1, and the other 6 people observed the MB sequence 2. The characteristics of each MB are described in Table 1 and presented in Figure 2. Figure 3a shows the sequences with the types of MB used in this study.

To study the eye movements in the visual reading process related to each Area Of Interest (AOI), we chose to divide the boards into nine AOI's (Figure 3b) and to interpret the following visualisation criteria, generated by the BeGaze software: (i) time to first fixation (time from the start of viewing until the participant fixates gaze for the first time on an AOI); (ii) average duration of fixations (average duration of all fixations on each AOI); (iii) fixation count (number of times the participant fixated on an AOI; (iv) revisit (number of times the participant returned to an AOI); (v) dwell time (time the participant spent looking at an AOI); (vi) sequence (sequence of visual reading of the AOI). The analysis was also performed with the help of the "heat map" resource to observe the places with higher and lower incidence of visualisation.

For this study, were used two laptop computers and one SMI Eye-tracking glasses. One laptop equipped with BeGaze v. 3.6 software for eye-tracking data capture and analysis. Another laptop was used to calibrate the tracking glasses and present the MB to the participant during the reading capture procedure.

Table 1. Boards used to compose the visualisation sequences.

\begin{tabular}{|c|c|c|}
\hline Boards & Characteristics & Objective \\
\hline \multirow{4}{*}{ Type A } & - A board composed of 13 image elements; & $\begin{array}{l}\text { Obtain data on the visual reading of all participants } \\
\text { to detect patterns, deviations and eventual disparities } \\
\text { in board reading; }\end{array}$ \\
\hline & $\begin{array}{l}12 \text { images of residential interiors, with varied visual } \\
\text { complexity and two primary colours (white and } \\
\text { brown); }\end{array}$ & $\begin{array}{l}\text { Obtain data to determine if variations in the number } \\
\text { of visual elements than other boards influence visual } \\
\text { reading behaviour. }\end{array}$ \\
\hline & $\begin{array}{l}\text { Textual elements containing the words "wood \& } \\
\text { white" and "mood"; }\end{array}$ & \\
\hline & $\begin{array}{l}\text { Used, without changes, in both visualisation } \\
\text { sequences. }\end{array}$ & \\
\hline & - Boards composed of 31 image elements; & \\
\hline Type B & $\begin{array}{l}31 \text { small images of decorative and monochrome } \\
\text { (black and white) objects of various sizes; } \\
\text { - Board B2 contains the same images as B1 but with } \\
\text { horizontally inverted positions. }\end{array}$ & $\begin{array}{l}\text { To obtain comparative data to assess whether } \\
\text { objects' position influences the visual reading } \\
\text { sequence. }\end{array}$ \\
\hline \multirow{3}{*}{ Type C } & $\begin{array}{l}\text { Boards composed of } 22 \text { image elements; } \\
\text {. } 21 \text { Images in intense, artificial colours and cool } \\
\text { tones; }\end{array}$ & \\
\hline & $\begin{array}{l}\text { One colour palette on the left of the board; } \\
\text { - One of the images includes an object in a contrasting } \\
\text { colour (orange); }\end{array}$ & $\begin{array}{l}\text { To obtain data indicating whether a visual element } \\
\text { with colour contrast influences visual reading } \\
\text { behaviour. }\end{array}$ \\
\hline & $\begin{array}{l}\text { The } \mathrm{C} 2 \text { board contains the same images as } \mathrm{C} 1 \text { but } \\
\text { in randomly switched positions. }\end{array}$ & \\
\hline
\end{tabular}



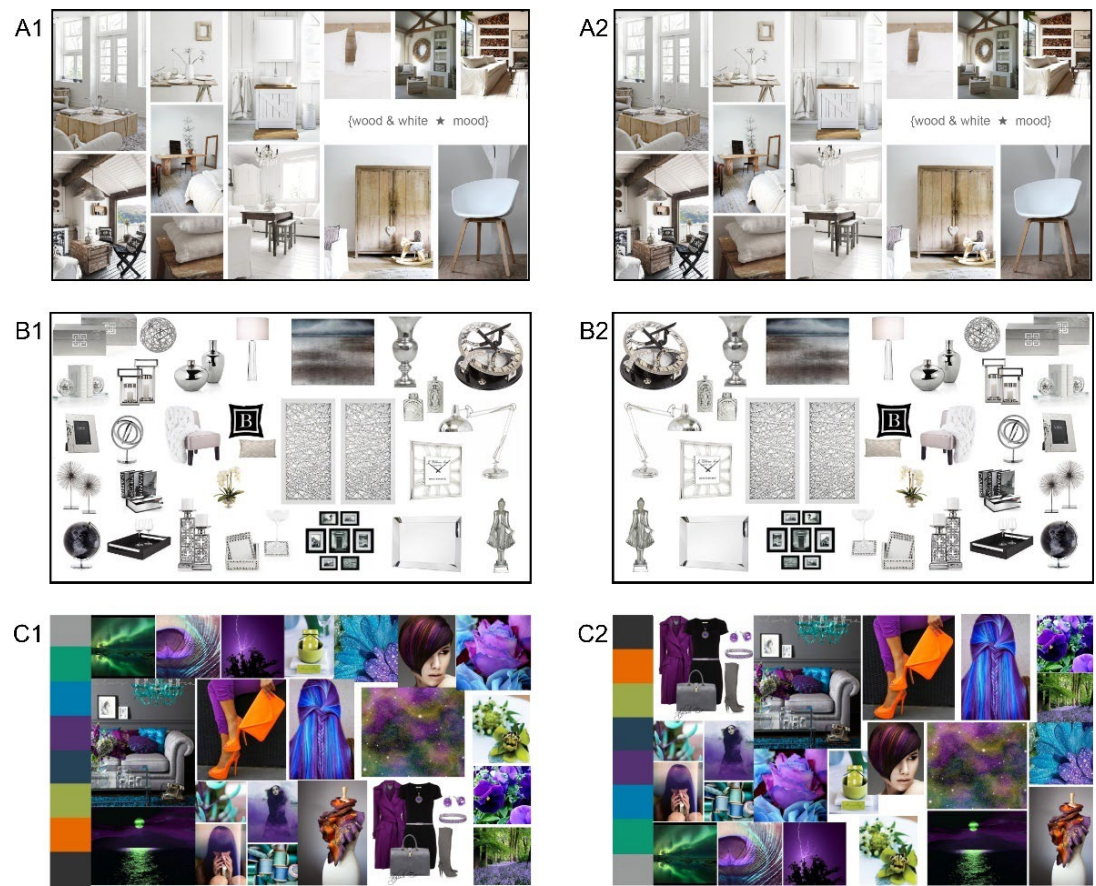

Figure 2. Boards used for the visual capture process.

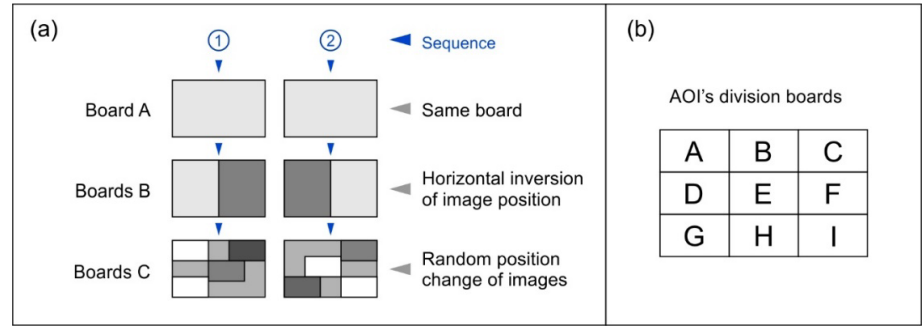

Figure 3. (a) Boards presentation sequence in the visual reading capture process. (b) Letters assigned to the nine MB Areas of Interest (AOI's).

With the results obtained, for each MB visualisation criterion identified, was evaluated if a statistical difference occurred (ANOVA analysis of variance - $p<0.05$ ): (a) between the same MB sequence (1 x 2); (b) between different boards of the same sequence (A x B x C); (c) different AOI of the MB (Figure 4). Furthermore, were conducted Pearson correlations to verify directly or inversely proportional behaviour between the results of the visualisation criteria. The StatSoft Statistic 12.0 software conducted all statistical analyses.

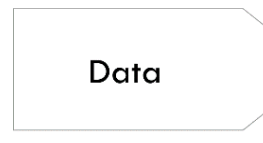

Obtained from BeGaze software

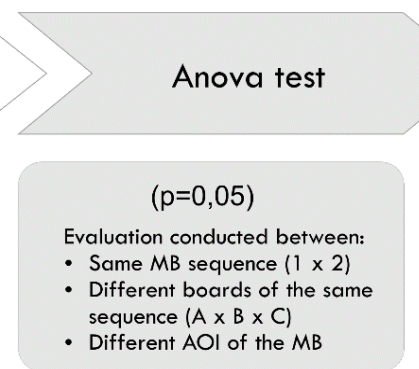

Figure 4. Statistical analysis procedure 
The results are shown, taking into consideration the data provided by the BeGaze software. Subsequently, a statistical analysis was presented regarding the data collected from the MB and their respective AOI, and finally, an integrative discussion of the results was conducted.

\section{Results}

\subsection{MB type observer influence}

Considering the data collected (Appendix 1), an exciting behaviour was identified with the participants' responses when different MB was observed (Figure 5). Firstly, different MB showed to influence the response of the viewers. The performance can be explained because there are no statistical differences $(p=>0.05)$ identified when comparing MB A1 and A2, as well as MB B1 and B2. In MB types A and B, there was no statistically significant difference between them. On the other hand, there was a statistical difference $(p=<0.05)$ with random images positions in MB type $\mathrm{C}$. In this case, changes in image positioning have been shown to influence the observer's perception, being a relevant point to be considered.
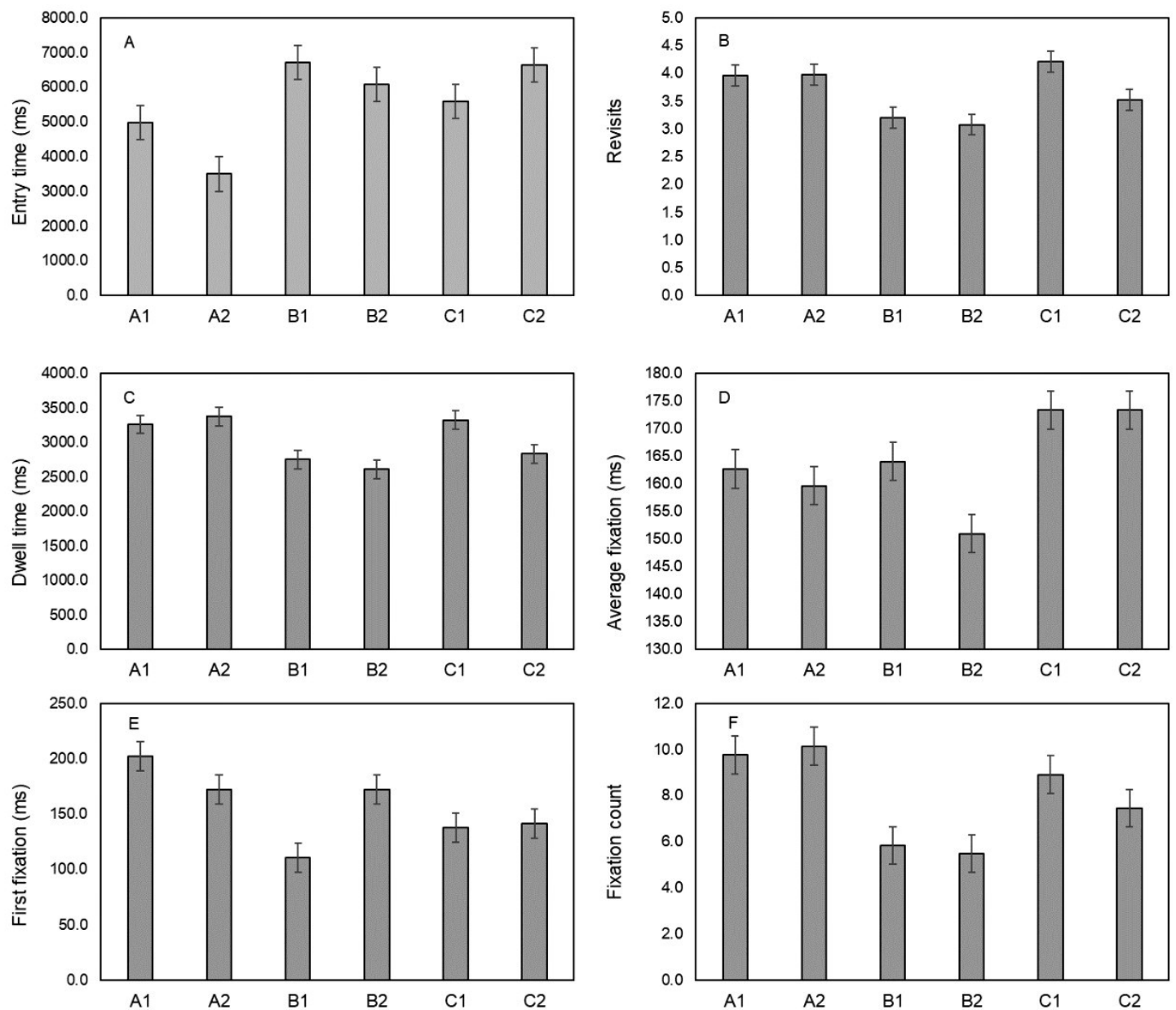

Figure 5. Visualization criteria mean values and standard deviation identified for each board. A) Entry time; B) Revisits; C) Dwell time; D) Average fixation; E) First fixation; F) Fixation count.

Furthermore, a statistical difference $(\mathrm{p}=>0.05)$ was also identified for all MB within the same sequence. These results evidenced that the image arrangement within an $\mathrm{MB}$ is a factor to be considered when constructing the MB.

Overall, Pearson correlations showed a significant inversely proportional association (-0.875) between average entry time and average fixation, indicating that the average fixation decreases when entry time increases, showing that the MB image set influenced these variables. The shortest average time required for the first input to occur, by the observer, in each AOI, was identified for MB A1 and A2 (average values of 5,044.5 and 3,501.2 $\mathrm{ms}$, respectively) when compared to the other MB (average values range from 5,594.2 to 6,718.0 ms). The longest 
average dwell time also occurred for the AI and A2 MB, with $29840.1 \mathrm{~ms}$, compared to the other MB, which has average values of $24137.4 \mathrm{~ms}$ for the $\mathrm{B} 1$ and $\mathrm{B} 2$ boards and $27584.1 \mathrm{~ms}$ for the $\mathrm{C} 1$ and $\mathrm{C} 2$ boards. This data seems to be associated with the number of imagery elements of the MB different types, pointing to a proportional relationship between boards. MB A1 and A2 have a smaller number of image elements than the others, with 13 elements. MB type B has 31 elements, and MB type C has 22 elements. The MB type $\mathrm{C}$ was the boards with a longer time for participants to fix their gaze (average values of $173.3 \mathrm{~ms}$ for $\mathrm{C} 1$ and $\mathrm{C} 2$ ) than the other $\mathrm{MB}$ (average values range from 151 to $164 \mathrm{~ms}$ ). This behaviour may be associated with the type of image used, with colours in exotic shades, generating a greater degree of curiosity and comparative observation between fantasy and reality.

Pearson correlations are directly proportional $(0.9835)$ between the dwell time, the time the participant spent looking at an MB AOI, and the number of revisits identified, indicating that when one variable increases, the other variable tends to increase as well. In this sense, MB A1 and A2 presented the longest dwell time (3259.2 and 3371.9 respectively), while the other $\mathrm{MB}$ presented mean values in the range of 2753.7 to 3318.9 . Simultaneously, the number of revisits was higher in A1, A2 and C1, with average values of 4 . The other MB had average values of around 3. A higher number of revisits in the MB may be related to a less attentive reading by the participant. It indicates a higher number of times that the participant returned to the same AOI. On the other hand, the longer dwell time may indicate a high level of interest in one or more specific AOI.

Based on the results obtained, the MB's sequence 1 had higher numerical values than sequence 2 for all the equipment's data. This behaviour showed that the reading performed by the participants of sequence 1 was less attentive than sequence 2 . However, the differences presented suggest that they were related to individual differences between the participants who made the observations.

\subsection{AOI influence on the MB visual reading}

To evaluate the influence of AOI on the board visual reading, MB were delimited into 9 areas to compare the obtained data between them. It can be identified that the AOI that most influenced the results varied for each type of MB. Statistical differences were observed for all the criteria evaluated between the different AOI of the different boards ( $\mathrm{p}>0.05)$.

A heat map was employed to show the aggregate fixations based on the results obtained (Figure 6). The results generated indicate a higher observation frequency in the central parts of the images when viewing the imagery elements individually. Pylyshyn (2003) points out that a variety of evidence suggests that visual attention operates - at least, in part - on whole objects rather than places or regions or any other spatially defined aspects. On the other hand, the map also points to a tendency by participants to direct their gaze to the lower third of the visualised imagery elements.
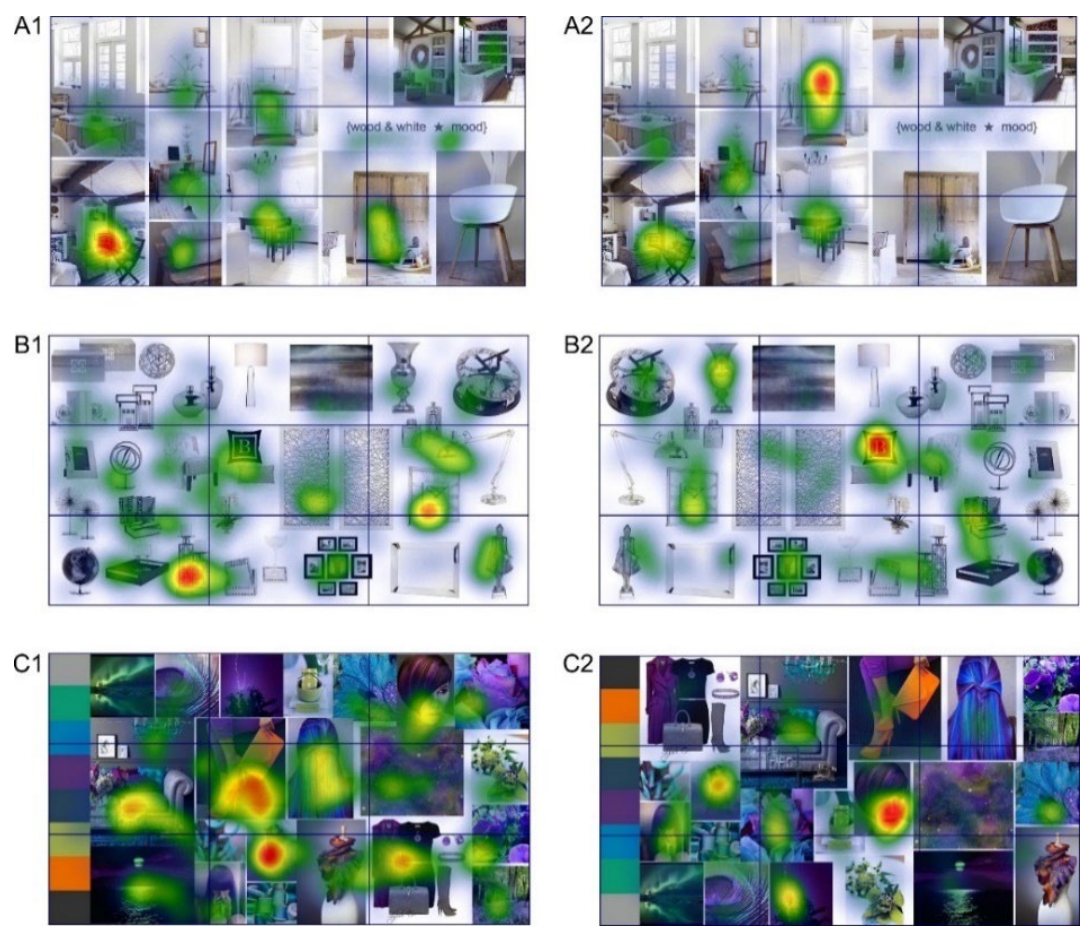

Figure 6. Heat map identified for each board. 
The most significant visual fixation points in the specific AOI of each board presented were highlighted (Figure 7). In MB type A, they occurred in AOI G. In MB type B and type C, they occurred in AOI E (centre of the board). The average fixation of all boards indicated a tendency to concentrate fixations in the central and lower board area. The data also indicate a reading pattern that differs from that observed in webpages, which point to the upper left area as the one with the highest concentration of visual readings (Faraday, 2000).

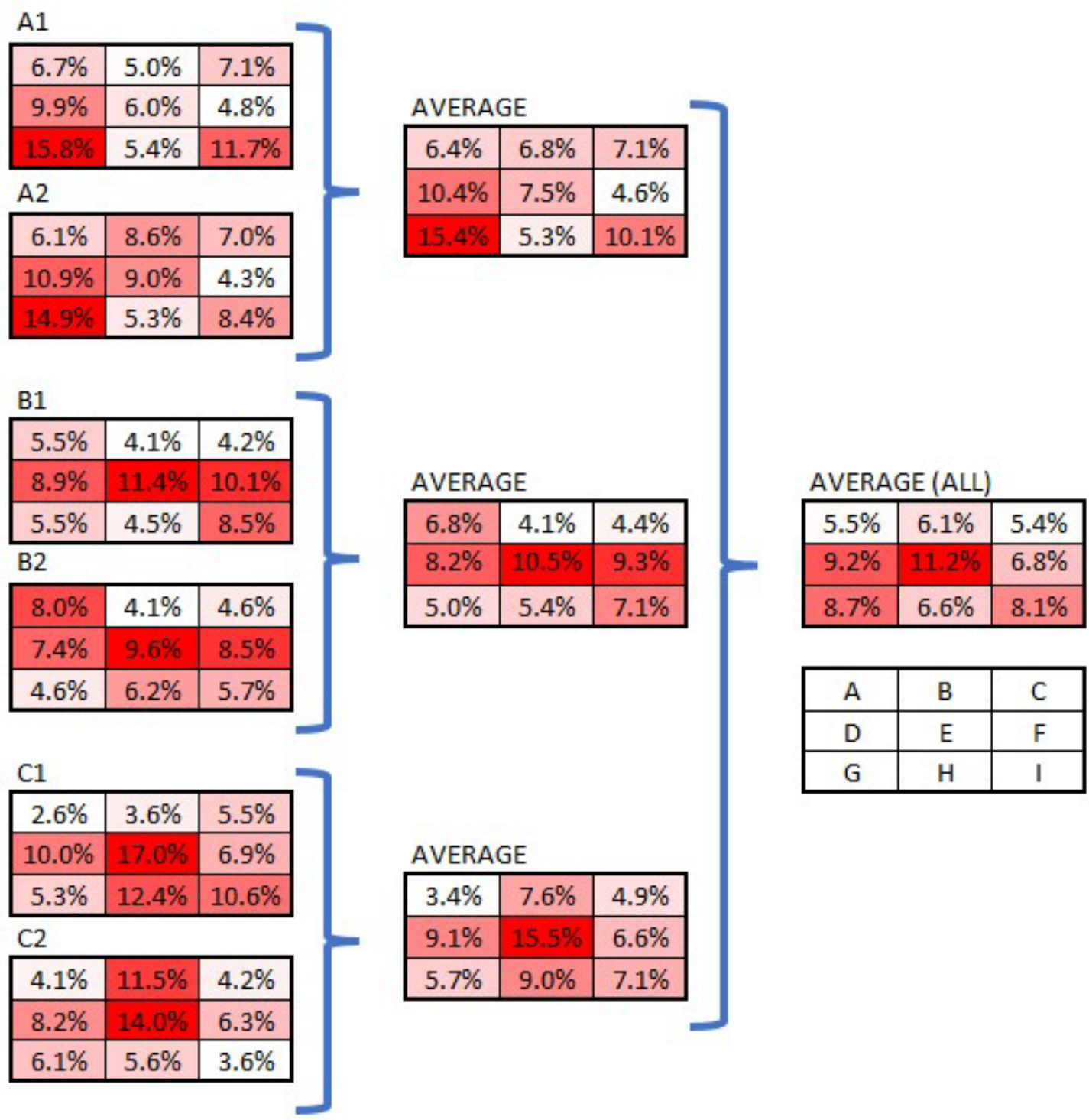

Figure 7. Average Dwell time. The red colour graduation indicates higher dwell time values.

Among boards of the same type, for $2 / 3$ of the AOI with the same position, in MB A, presented values in the fixations are close, suggesting a similar visual behaviour among participants. In MB type B, with inverted horizontal compositions, an approximation of values between similar AOI was also detected, suggesting that the simple inversion in the imagery compositions does not reflect a similar behaviour in viewing the board. In MB type $\mathrm{C}$, which presents a contrast object (orange), an increment in the fixation value was detected when the object was in the respective AOI. The board $\mathrm{C}$, with the contrast object in AOI E, the fixation recorded in this AOI was $17.0 \%$, the highest percentual in the whole fixation data capture, while the value for AOI B was $3.6 \%$. It is possible to deduce that this $17.0 \%$ value obtained in AOI E results from the centre of the board and the contrast object. The board $\mathrm{C} 2$, with the object in AOI B, the fixation recorded was $11.5 \%$, and the value recorded for AOI $\mathrm{E}=14.0 \%$. This change suggests that, even in situations of close observation, the use of contrast elements influences the visualisation of an MB. Colours can exert a strong emotional and behavioural appeal (Cyr et al., 2010) and, in this case, may also exert some influence on the visual reading process. 


\section{Conclusion}

Based on an MB visual reading process analysis linked to different viewers, the image position and physical characteristics that influence an attentive MB visual reading were identified. Thus, it can be concluded that:

Based on the different data identified for different MB types, image positioning influenced the viewer's perception, which is a relevant point to be considered when assembling the MB's image composition.

The AOI that most influenced the results varied for each MB. However, a tendency was identified on the participant to concentrate the readings in the central area and the lower and left halves of the boards, overlapping the characteristics applied between the MB used (inversion in image composition and contrast by colour).

Considering the reading of an $\mathrm{MB}$ as an action of attentive reading, in which the observer operates a visual scan, visual resources, such as the colour contrast presented in boards $\mathrm{C}$, proved effective in creating differentiated areas of visual attraction. In this sense, contrasting images is a visual resource to be observed when composing an MB.

Eye-tracking equipment effectively detects visualisation actions, presents AOI data, and compares the different MB. The time for visual reading of each board (40 s) was adequate for complete visualisation and data collection. However, in research involving the analysis of average fixations, the exposure time should be extended to allow participants to perform average fixations between 200 and 300 milliseconds. According to Granka et al. (2008, p. 348), this is the period "[...] during which visual attention is directed to a specific area of the visual display".

As an opportunity for future research, studies can be carried out with other imagery compositions, evaluating background colours, sizes and orientation of images, geometric elements, objects (on physical boards) and videos that influence the reading. Research involving the format, location, access and quantity of MB may also improve its efficiency as a tool.

\section{References}

Arnheim, R. (1982). The Power of the Center: a study of composition in the visual arts. Berkeley: University of California Press. https://doi.org/10.2307/3332229

Arnheim, R. (2004). Art and visual perception: a psychology of the creative eye (2nd ed.). Berkeley: University of California Press. Baxter, M. (2011). Projeto de Produto: guia prático para o design de novos produtos (3rd ed.). São Paulo: Edgard Blücher. Bruseberg, A., McDonagh, D., \& Wormald, P. (2003). The use of images to elicit user needs for the design of playground equipment. In D. McDonagh, P. Hekkert, J. van Erp, \& D. Gyi (Eds.), Design and emotion (pp. 114-118). CRC Press. https://doi.org/10.1201/9780203608173-c21

Cassidy, T. (2008). Mood boards: current practice in learning and teaching strategies and students' understanding of the process. International Journal of Fashion Design, Technology and Education, 1(1), 43-54. http://dx.doi.org/10.1080/17543260802015154.

Cassidy, T. (2011). The mood board process modeled and understood as a qualitative design research tool. Fashion Practice, 3(2), 225-251. http://dx.doi.org/10.2752/175693811X13080607764854.

Chang, H.-M., Díaz, M., Català, A., Chen, W., \& Rauterberg, M. (2014). Mood boards as a universal tool for investigating emotional experience. In Lecture Notes in Computer Science (including subseries Lecture Notes in Artificial Intelligence and Lecture Notes in Bioinformatics): Vol. 8520 LNCS (Pt 4, pp. 220-231). Springer. https://doi.org/10.1007/978-3-319-07638-6_22.

Collewijn, H. (1998). Eye movement recording. In R. Carpenter \& J. Robson (Eds.), Vison research: a practical guide to laboratory methods (pp. 245-285). Oxford: Oxford University Press.

Cyr, D., Head, M., \& Larios, H. (2010). Colour appeal in website design within and across cultures: a multi-method evaluation. International Journal of Human-Computer Studies, 68(1-2), 1-21. http://dx.doi.org/10.1016/j.ijhcs.2009.08.005.

Damasceno, P. L., \& Gruszynski, A. (2014). Design de jornais - processos, rotinas e produto: um estudo do Segundo Caderno, suplemento cultural de Zero Hora. Brazilian Journalism Research, 10(1), 108-127. Retrieved in 2021, September 3, from https://bjr.sbpjor.org.br/bjr/article/viewFile/551/530

Djamasbi, S., Siegel, M., Skorinko, J., \& Tullis, T. (2011). Online viewing and aesthetic preferences of generation y and the baby boom generation: testing user web site experience through eye tracking. International Journal of Electronic Commerce, 15(4), 121158. http://dx.doi.org/10.2753/JEC1086-4415150404.

Edwards, A., Fadzli, S. A., \& Setchi, R. (2009). A comparative study of developing physical and digital mood boards. Proceeding Innovative Production Machines and Systems, 1-6.

Faraday, P. (2000). Visually critiquing web pages. In N. Correia, T. Chambel \& G. Davenport (Eds.), Multimedia '99. Eurographics. Vienna: Springer. https://doi.org/10.1007/978-3-7091-6771-7_17.

Findlay, J. M., \& Gilchrist, I. D. (2003). Active Vision: the psychology of looking and seeing. Oxford: Oxford University Press. https://doi.org/10.1093/acprof:oso/9780198524793.001.0001

Gade, U. T. (2016). Design boards as an alignment tool for cross-disciplinarity in engineering. In E. Bohemia, L. Buck, K. Eriksen, A. Kovacevic, N. Ovesen \& C. Tollestrup (Eds.), Proceedings of the 18th International Conference on Engineering and Product Design Education: Design Education: Collaboration and Cross-Disciplinarity, E and PDE 2016. Institution of Engineering Designers, The Design Society. 
Garner, S., \& McDonagh-Philp, D. (2001). Problem Interpretation and Resolution via Visual Stimuli: The Use of 'Mood Boards' in Design Education. International Journal of Art \& Design Education, 20(1), 57-64. http://dx.doi.org/10.1111/1468-5949.00250.

Godlewsky, T. (2008). Mood board. In M. Erlhoff \& T. Marshall (Eds.), Design dictionary: perspectives on design terminology (pp. 266). Birkhäuser Basel. https://doi.org/10.1007/978-3-7643-8140-0_173.

Gonçalves, M., Cardoso, C., \& Badke-schaub, P. (2014). What inspires designers? Preferences on inspirational approaches during idea generation. Design Studies, 35(1), 29-53. http://dx.doi.org/10.1016/j.destud.2013.09.001.

Granka, L. A., Feusner, M., \& Lorigo, L. (2008). Eye monitoring in online search. In R. I. Hammoud (Ed.), Passive Eye Monitoring: algorithms, application and experiments (pp. 347-372). Springer-Verlag. https://doi.org/10.1007/978-3-540-75412-1

Hooge, I. T. C., \& Erkelens, C. J. (1998). Adjustment of fixation duration in visual search. Investigative Ophthalmology \& Visual Science, 38(4), 1295-1302.

Hübner, R., \& Thömmes, K. (2019). Symmetry and balance as factors of aesthetic appreciation: Ethel Puffer's (1903) 'Studies in Symmetry’ revised. Symmetry, 11(12), http://dx.doi.org/10.3390/SYM11121468.

Koch, J., Taffin, N., Lucero, A., \& Mackay, W. E. (2020). SemanticCollage: enriching digital mood board design with semantic labels. DIS 2020 - Proceedings of the 2020 ACM Designing Interactive Systems Conference, 407-418. https://doi.org/10.1145/3357236.3395494.

Leyssen, M. H. R., Linsen, S., Sammartino, J., \& Palmer, S. E. (2012). Aesthetic preference for spatial composition in multiobject pictures. I-Perception, 3(1), 25-49. http://dx.doi.org/10.1068/i0458aap.

Löbach, B. (2001). Design Industrial: bases para a configuração dos produtos industriais. São Paulo: Edgard Blücher.

Locher, P. J., \& Stappers, P. J. (2002). Factors contributing to the implicit dynamic quality of static abstract designs. Perception, 31(9), 1093-1107. http://dx.doi.org/10.1068/p3299.

Locher, P., Overbeeke, K., \& Stappers, P. J. (2005). Spatial balance of color triads in the abstract art of Piet Mondrian. Perception, 34(2), 169-189. http://dx.doi.org/10.1068/p5033.

Lucero, A. (2015). Funky-design-spaces: interactive environments for creativity inspired by observing designers making mood boards. In J. Abascal, S. Barbosa, M. Fetter, T. Gross, P. Palanque, \& M. Winckler (Eds.), Lecture Notes in Computer Science (including subseries Lecture Notes in Artificial Intelligence and Lecture Notes in Bioinformatics) (Vol. 9298, pp. 474-492). Springer International Publishing. https://doi.org/10.1007/978-3-319-22698-9_32

Lucero, A. (2012). Framing, aligning, paradoxing, abstracting, and directing: how design mood boards work. In Proceedings of the Designing Interactive Systems Conference, DIS ’12 pp. (438-447). https://doi.org/10.1145/2317956.2318021.

Martin, B., \& Hanington, B. (2012). Universal methods of design: 100 ways to research complex problems, develop innovative ideas, and design effective solutions. USA: Rockport Publishers. https://doi.org/10.5860/CHOICE.49-5403.

McDonagh, D., Bruseberg, A., \& Haslam, C. (2002). Visual product evaluation: exploring users' emotional relationships with products. Applied Ergonomics, 33(3), 231-240. http://dx.doi.org/10.1016/S0003-6870(02)00008-X.

McDonagh, D., \& Denton, H. (2005). Exploring the degree to which individual students share a common perception of specific mood boards: observations relating to teaching, learning and team-based design. Design Studies, 26(1), 35-53. http://dx.doi.org/10.1016/j.destud.2004.05.008

Pashler, H. E. (1999). The psychobgy of attention. Cambridge: MIT Press.

Pazmino, A. V. (2015). Como Se Cria: 40 métodos para design de produtos. São Paulo: Edgard Blücher.

Pereira, T. V. (2010). Mood Board como espaço de construção de metáforas. UNISINOS. Retrieved in 2021, September 3 , from http://www.repositorio.jesuita.org.br/handle/UNISINOS/3029.

Pernice, G., \& Nielsen, J. (2009). How to Conduct Eyetracking Studies. Fremont: Nielson Norman Group.

Pylyshyn, Z. W. (2003). Seeing and Visualizing: it's not what you think. London: Bradford Book.

Rieuf, V. (2013). Impact of the immersive experience on kansei during early design [Arts et Métiers ParisTech]. Retrieved in 2021, September 3 ,

from http://www.academia.edu/download/32204012/Impact_of_the_Immersive_Experience_on_Kansei_During_Early_Immersive_ -_Vincent_RIEUF___LCPI.pdf

Sternberg, R. J. (2010). Psicologia cognitiva (5th ed.). Boston: Cengage Learning

Wilson, A., \& Chatterjee, A. (2005). The assessment of preference for balance: introducing a new test. Empirical Studies of the Arts, 23(2), 165-180. http://dx.doi.org/10.2190/b1lr-mvf3-f36x-xr64.

Yamani, Y., McCarley, J. S., \& McDonagh, D. (2010). Transgenerational communication through affective imagery in mood boards. Proceedings of the Human Factors and Ergonomics Society Annual Meeting, 54(20), 1762-1765. http://dx.doi.org/10.1177/154193121005402004.

Zelinsky, G. J., Rao, R. P. N., Hayhoe, M. M., \& Ballard, D. H. (1997). Eye movements reveal the spatiotemporal dynamics of visual search. Psychological Science, 8(6), 448-453. 
Appendix 1. Data provided by BeGaze software.

\begin{tabular}{|c|c|c|c|c|c|c|c|c|}
\hline Board & AOI & Sequence & $\begin{array}{c}\text { Entry time } \\
(\mathrm{ms})\end{array}$ & $\begin{array}{c}\text { Dwell time } \\
(\mathrm{ms})\end{array}$ & Revisits & $\begin{array}{c}\text { Average } \\
\text { fixation }(\mathrm{ms})\end{array}$ & $\begin{array}{c}\text { First fixation } \\
(\mathrm{ms})\end{array}$ & $\begin{array}{c}\text { Fixation } \\
\text { count }\end{array}$ \\
\hline \multirow{9}{*}{ A1 } & A & 2 & 2576.9 & 2704.5 & 3.0 & 143.8 & 210.6 & 6.3 \\
\hline & B & 7 & 7453.7 & 2031.1 & 2.9 & 129.5 & 205.1 & 6.2 \\
\hline & $\mathrm{C}$ & 9 & 8224.0 & 2865.1 & 3.0 & 219.6 & 188.4 & 6.2 \\
\hline & $\mathrm{D}$ & 1 & 2327.5 & 4028.9 & 6.0 & 137.5 & 166.2 & 12.5 \\
\hline & $\mathrm{E}$ & 4 & 3882.0 & 2430.1 & 2.9 & 84.7 & 205.1 & 6.2 \\
\hline & $\mathrm{F}$ & 6 & 5419.8 & 1945.2 & 4.2 & 141.8 & 166.2 & 9.5 \\
\hline & G & 8 & 7752.9 & 6422.8 & 4.7 & 214.3 & 205.0 & 17.7 \\
\hline & $\mathrm{H}$ & 3 & 3391.6 & 2172.4 & 3.9 & 157.5 & 310.3 & 8.7 \\
\hline & I & 5 & 4372.4 & 4732.9 & 5.2 & 235.5 & 160.7 & 14.7 \\
\hline \multirow{10}{*}{ A2 } & Average & & 5044.5 & 3259.2 & 4.0 & 162.7 & 202.0 & 9.8 \\
\hline & A & 7 & 5287.0 & 2493.9 & 3.0 & 126.7 & 177.3 & 6.0 \\
\hline & B & 8 & 1490.8 & 3480.3 & 3.5 & 131.1 & 177.4 & 10.0 \\
\hline & $\mathrm{C}$ & 9 & 8733.9 & 2848.5 & 3.2 & 243.5 & 238.3 & 6.8 \\
\hline & $\mathrm{D}$ & 4 & 2621.3 & 4450.1 & 6.3 & 149.1 & 171.8 & 13.5 \\
\hline & E & 2 & 1490.8 & 3670.6 & 3.5 & 84.4 & 155.2 & 10.0 \\
\hline & $\mathrm{F}$ & 1 & 1052.9 & 1767.8 & 2.0 & 175.3 & 138.6 & 7.8 \\
\hline & G & 5 & 4234.0 & 6062.8 & 5.0 & 214.3 & 182.9 & 16.7 \\
\hline & $\mathrm{H}$ & 3 & 1712.4 & 2154.0 & 4.5 & 146.5 & 155.2 & 8.8 \\
\hline & I & 6 & 4887.9 & 3419.3 & 4.8 & 165.9 & 155.2 & 11.7 \\
\hline \multirow{10}{*}{ B1 } & Average & & 3501.2 & 3371.9 & 4.0 & 159.6 & 172.4 & 10.1 \\
\hline & A & 5 & 6395.2 & 2222.3 & 2.3 & 178.7 & 127.5 & 6.0 \\
\hline & B & 7 & 8916.8 & 1662.5 & 1.7 & 154.6 & 61.0 & 4.0 \\
\hline & $\mathrm{C}$ & 6 & 7947.0 & 1715.1 & 1.4 & 120.0 & 99.7 & 2.7 \\
\hline & $\mathrm{D}$ & 9 & 10080.6 & 3862.8 & 3.8 & 201.6 & 155.2 & 7.2 \\
\hline & $\mathrm{E}$ & 2 & 3009.2 & 4680.1 & 6.2 & 140.9 & 110.8 & 9.7 \\
\hline & $\mathrm{F}$ & 1 & 2139.1 & 4134.3 & 4.2 & 179.3 & 116.4 & 6.7 \\
\hline & G & 4 & 6324.3 & 1241.3 & 2 & 173.4 & 133.0 & 3.5 \\
\hline & $\mathrm{H}$ & 3 & 5658.2 & 1834.4 & 3.5 & 141.1 & 66.5 & 5.7 \\
\hline & I & 8 & 9991.9 & 3424.9 & 3.7 & 186.6 & 127.5 & 7.0 \\
\hline \multirow{10}{*}{ B2 } & Average & & 6718.0 & 2753.1 & 3.2 & 164.0 & 110.8 & 5.8 \\
\hline & A & 2 & 1895.3 & 3241.9 & 2.4 & 167.6 & 149.6 & 5.7 \\
\hline & B & 8 & 10108.3 & 1665.3 & 2.6 & 118.0 & 127.5 & 4.5 \\
\hline & $\mathrm{C}$ & 9 & 12951.2 & 1898.1 & 1 & 122.3 & 88.7 & 2 \\
\hline & $\mathrm{D}$ & 1 & 1582.7 & 3017.4 & 4.2 & 141.2 & 127.4 & 8 \\
\hline & $\mathrm{E}$ & 4 & 2200.1 & 3921.0 & 4.5 & 152.0 & 83.1 & 6.2 \\
\hline & $\mathrm{F}$ & 5 & 6350.9 & 3447.0 & 3.5 & 137.8 & 99.8 & 7 \\
\hline & G & 6 & 7675.4 & 1435.4 & 2.3 & 143.1 & 110.8 & 4.5 \\
\hline & $\mathrm{H}$ & 3 & 2100.3 & 2532.6 & 4.5 & 188.8 & 127.5 & 6.7 \\
\hline & I & 7 & 9870.0 & 2338.6 & 2.7 & 187.9 & 177.3 & 4.7 \\
\hline \multirow{11}{*}{ C1 } & Average & & 6081.6 & 2610.8 & 3.1 & 151.0 & 121.3 & 5.5 \\
\hline & A & 7 & 7867.2 & 1080.7 & 2.0 & 141.5 & 127.4 & 3.0 \\
\hline & B & 9 & 12045.2 & 1452.0 & 1.6 & 141.3 & 99.7 & 2.5 \\
\hline & $\mathrm{C}$ & 8 & 9886.6 & 2238.9 & 2.2 & 179.5 & 149.6 & 5.2 \\
\hline & $\mathrm{D}$ & 3 & 3408.2 & 4123.0 & 5.7 & 163.3 & 127.5 & 16.0 \\
\hline & $\mathrm{E}$ & 1 & 116.4 & 7010.4 & 10.3 & 201.7 & 166.3 & 17.2 \\
\hline & $\mathrm{F}$ & 2 & 2416.2 & 2815.2 & 5.3 & 187.3 & 133.0 & 10.2 \\
\hline & G & 4 & 3602.2 & 1745.7 & 2.8 & 182.6 & 177.4 & 7.7 \\
\hline & $\mathrm{H}$ & 6 & 6073.7 & 5104.0 & 3.8 & 175.2 & 121.8 & 7.7 \\
\hline & I & 5 & 4932.2 & 4300.3 & 4.2 & 187.8 & 138.6 & 10.7 \\
\hline & Average & & 5594.2 & 3318.9 & 4.2 & 173.3 & 137.9 & 8.9 \\
\hline
\end{tabular}


Appendix 1. Continued...

\begin{tabular}{|c|c|c|c|c|c|c|c|c|}
\hline Board & AOI & Sequence & $\begin{array}{c}\text { Entry time } \\
(\mathrm{ms})\end{array}$ & $\begin{array}{c}\text { Dwell time } \\
(\mathrm{ms})\end{array}$ & Revisits & $\begin{array}{c}\text { Average } \\
\text { fixation (ms) }\end{array}$ & $\begin{array}{c}\begin{array}{c}\text { First fixation } \\
(\mathrm{ms})\end{array} \\
\end{array}$ & $\begin{array}{c}\text { Fixation } \\
\text { count }\end{array}$ \\
\hline \multirow{10}{*}{$\mathrm{C} 2$} & A & 8 & 9310.2 & 1657.0 & 2.8 & 178.6 & 166.3 & 8.3 \\
\hline & B & 3 & 5148.3 & 4633.0 & 5.2 & 189.3 & 116.4 & 12.8 \\
\hline & $\mathrm{C}$ & 5 & 7032.6 & 1684.7 & 2.5 & 173.4 & 182.9 & 5.5 \\
\hline & D & 2 & 4993.2 & 3302.8 & 3.0 & 143.6 & 44.3 & 6.3 \\
\hline & E & 1 & 493.2 & 5564.2 & 8.0 & 188.7 & 149.6 & 11.2 \\
\hline & $\mathrm{F}$ & 4 & 6711.2 & 2532.5 & 2.5 & 195.3 & 199.5 & 6.7 \\
\hline & G & 7 & 7520.3 & 2438.4 & 3.2 & 173.5 & 121.9 & 5.5 \\
\hline & $\mathrm{H}$ & 9 & 11161.2 & 2233.4 & 2.3 & 175.9 & 149.6 & 6.3 \\
\hline & I & 6 & 7354.0 & 1452.0 & 2.2 & 141.9 & 144.1 & 4.5 \\
\hline & Average & & 6636.0 & 2833.1 & 3.5 & 173.3 & 141.6 & 7.5 \\
\hline
\end{tabular}

